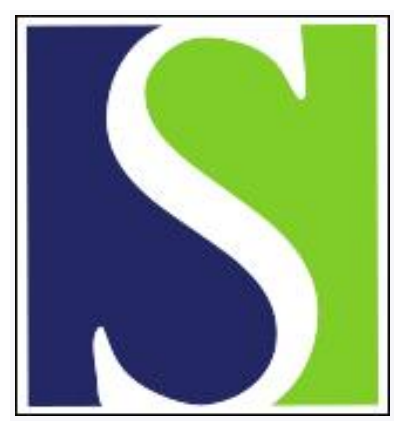

Scand J Work Environ Health 2005;31(1):1-2

https://doi.org/10.5271/sjweh.842

Issue date: Feb 2005

Reversed causality--a need to revisit systems modeling of work-stress-health relationships

by Kalimo $R$

Key terms: editorial; reversed causality; systems modeling; work-stress-health relationship

This article in PubMed: www.ncbi.nlm.nih.gov/pubmed/15751613

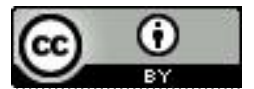




\section{Reversed causality—a need to revisit systems modeling of work-stress-health relationships}

In this issue of the Scandinavian Journal of Work, Environment \& Health, the article "Effect of Mental Health on Work Characteristics" (1) by de Lange and her colleagues tackles a stimulating question on reversed causality in research on work stress and occupational (mental) health.

The objective of the study on which this article is based is to assess the impact of (mental) health on work characteristics (and to prove the causal relationships in this direction) - and not vice versa, as is usually done in research on occupational health. This orientation is relatively new, but the really original feature of this paper is its effort to investigate the mechanisms that may explain these relationships among the healthy and nonhealthy job changers and stayers. The study is based on a large sample of longitudinal data, with repeated measurements on work conditions and health, and this basis belongs to the strong points of the empirical part of the study. The data are dealt with in sophisticated statistical analyses including structural equation modeling.

The authors justifiably point out that there has been minimal information about the effects of mental health on work conditions until very recently. While admittedly this is a new approach in empirical health research, it is obvious that the approach was present in theory construction already in the 1970s when the first major, largely adopted work-stress-health models were published. Perhaps the most representative of these is the "theoretical model for psychosocially mediated disease" by Kagan \& Levi (2). That model was based on systems thinking involving environmental and human components. Typical to systems thinking in occupational health is the effort to understand the work environment, health, and complex interacting factors and mechanisms as an integrated dynamic structure (system), in which the parts interact with each other in many directions. The main flow of events in the model is thought to proceed from social structure and process to psychosocial stimuli and, from them, further through a psychobiological program to pathogenic mechanisms and precursors of disease and, finally, to disease, modified at each step by various interacting factors. This model was described by its authors on many occasions, and, in one of the articles, Levi (3) states: "All of these interactions take place in a man-environment ecosystem. The process ... is not a one-way flow in a simple, linear, or even multi-factorial model but constitutes a non-linear, cybernetic system with continuous feedback. Accordingly, if disease has occurred in an individual, it has repercussions on the social processes within the social structure ... [p 11]". Hence the theoretical basis for the present problem was laid at least as early as the 1970s. Although the terminology of the model currently seems partly outdated, its main principles are worth a revisit.

This and some other corresponding models have largely been adopted as the basis of thinking since their publication. System thinking was on the rise and á la mode. Empirical research on work, stress, and occupational health, however, started to focus solely on the impacts of work on health, occasionally recognizing additional factors as modifiers of this interrelationship. The main approach has remained as such until very recently. Why was system thinking forgotten in empirical research on work conditions, stress, and health? One explanation is that there was an urge to prove that psychological and social factors related to work conditions should be recognized as determinants of health. This aspect was linked with the spirit of the time within the expanding field of occupational health.

Has empirical research now reached the phase where environmental factors are considered to modify health, which, again, modifies the environment, all in interaction with a multitude of other factors or, when said with other words, are the parts of the system linked with each other? This article looks at the sequence from health to environment, called reversed causality, and thus turns over the causal sequence investigated in previous empirical studies. Some other studies have recognized both directions, testing what is called reciprocal causation [eg, the 
work of de Jonge et al (4)]. Dynamic integrative thinking and the modeling of multiple interrelationships remain yet to be strengthened and adopted as the basis of empirical research.

The more research proceeds in encompassing the whole system, the more inappropriate the current use of some concepts will probably seem (eg, reversed causality and normal causality). They derive from methodological approaches to the problem rather than from a focus on its content. From a systemic point of view, both chains of causation can be regarded as normal, although one may be stronger than the other and one may be considered as the main causal path while the other is more peripheral or secondary. The causal path considered less important has merely been neglected in empirical studies. de Lange and her colleagues deserve to be acknowledged for bringing an important aspect of the long-term theoretical understanding into the focus of field investigation.

The study showed that (mental) health affected perceived work characteristics both positively and negatively via different mechanisms, depending on the subgroup of employees. The positive effects of health on perceived work characteristics were interpreted as results of the rosy perception mechanism, while the gloomy perception mechanism explained the negative effects of health on work characteristics for employees remaining in a stable work situation. For job changers, only positive effects on work characteristics (control) were found, and they were independent of health.

The authors rightly conclude that a change in self-reported work characteristics in the case of the stayers may not always indicate perceptual change only, either rosy or gloomy, but may also cover up real changes. It would be of major practical interest to know to what extent work conditions have been purposefully or unnoticedly adapted to the health needs of employees. This matter could not be investigated in the study by de Lange et al, because information about possible changes implemented at the workplace was not available. In general, the responsiveness of workplaces to variation in the status of the health of the workforce would be an important problem for future study.

The job changers experienced only positive outcomes in the form of increased control at work, characterized by the authors as a promotion mechanism in which health played no significant role.

Change of job and its consequences may be strongly culturally dependent, and, therefore, these findings are probably the least generalizable results of the study. On the whole, the question is one of the complex issues of job turnover, in which a multitude of social factors can modify the possible role played by health.

On the whole, this study on the effects of mental health on work characteristics and another article called "Disentangling the Causal Relationships Between Work-home Interference and Employee Health" by van Hooff et al (5) in this issue of the Scandinavian Journal of Work, Environment \& Health are both important contributions because of their specific findings and their ability to remind us of the occupational stress and health research on the complexity of the causation of the work-stress-health relationships. Among the many interesting and stimulating issues of discussion, they pinpoint a novel variety of mediating mechanisms in work and mental health and confirm the need to recognize the differences between various subpopulations.

\section{References}

1. de Lange AH, Taris TW, Kompier MAJ, Houtman ILD, Bongers PM. Different mechanisms to explain the reversed effects of mental health on work characteristics. Scand J Work Environ Health 2005:31;3-14.

2. Kagan AR, Levi L. Health and environment—psychosocial stimuli: a review. In: Levi L, editor. Society, stress and disease: childhood and adolescence; vol 2. London, New York \& Toronto: Oxford University Press; 1975. p 241-60.

3. Levi L. Definitions and the conceptual aspects of health in relation to work. In Kalimo R, El-Batawi MA, Cooper C, editors. Psychosocial factors at work and their relation to health. Geneva: World Health Organization; 1987. p $9-14$.

4. de Jonge J, Dormann C, Janssen PPM, Dollard MF, Landeweerd JA, Nijhuis FJN. Testing reciprocal relationships between job characteristics and psychological well-being: a cross-lagged structural equation model. J Occup Organ Psychol 2001;74:29-46.

5. van Hooff MLM, Geurts SAE, Taris TW, Kompier MAJ, Dikkers JSE, Houtman ILD, et al. Disentangling the Causal Relationships Between Work-home Interference and Employee Health. Scand J Work Environ Health 2005:31:15-29. 